\section{Vertebral height as the measure of lesion length in carcinoma of the oesophagus is it accurate?}

\begin{tabular}{|c|}
\hline $\begin{array}{l}\text { V Sharma } \\
M D, P h D\end{array}$ \\
\hline $\begin{array}{c}\text { B Donde } \\
\text { MB BCh, MMed Rad (t) }\end{array}$ \\
\hline $\begin{array}{l}\text { M Mohiuddin } \\
\text { MB BS, MMed Rad (Onc) }\end{array}$ \\
\hline $\begin{array}{c}\text { B S Rabin } \\
\text { MB BCh, MMed Rad (t) }\end{array}$ \\
\hline $\begin{array}{c}\text { U Majeed } \\
\text { MB BS, FFRad (Onc) }\end{array}$ \\
\hline $\begin{array}{l}\text { D Chetty } \\
\text { мв ChB }\end{array}$ \\
\hline $\begin{array}{c}\text { C Nyongensa } \\
\text { MB BS }\end{array}$ \\
\hline $\begin{array}{c}\text { A Msemo } \\
\text { MB BS } \\
\text { Department of Radiation Oncology, } \\
\text { Johannesburg Hospital and University of the } \\
\text { Witwatersrand }\end{array}$ \\
\hline $\begin{array}{c}\text { D van der Merwe } \\
\text { PhD } \\
\text { Department of Medical Physics, } \\
\text { Johannesburg Hospital and University of the } \\
\text { Witwatersrand }\end{array}$ \\
\hline $\begin{array}{l}\text { R Glynn-Thomas } \\
\text { MB BCh, DMRD (RCP, RCS) } \\
\text { Department of Radiology, Johannesburg } \\
\text { Hospital and University of the Witwatersrand }\end{array}$ \\
\hline
\end{tabular}

ment length and the number of normal oesophageal mucosa in the treatment volume, thereby reducing the chance of treatment-related complications such as strictures and ulceration.

\section{Introduction}

The majority of patients with carcinoma of the oesophagus present with advanced stage disease and poor prognosis, with difficulty in swallowing as the major presenting symptom. ${ }^{1}$ Intraluminal radiation therapy is useful for controlling the endoluminal disease and this treatment modality leads to rapid improvement in swallowing. Various authors have published on the use of low and high dose rate intraluminal brachytherapy alone or in combination with external beam radiation therapy for the palliation of advanced oesophageal cancer. $^{2-5}$ Ideally, the palliative treatment should not aggravate the patient's symptoms by causing treatmentrelated toxicity or complications. The purpose of the modified technique is: (i) accurate assessment of the length of the lesion on Hexabrix swallow; and (ii) to decrease the fluoroscopy time during the procedure, thereby reducing staff exposure to radiation.

\section{Methods and materials}

Ten consecutive patients due for intraluminal radiation therapy for carcinoma of the oesophagus underwent the modified technique of simulation with Hexabrix using the magnification graticule with the grid projecting at $1 \mathrm{~cm}$ interval at the isocentre prior to the procedure (Fig. 1). The length of the lesion and the centre of 


\section{ORIGINAL ARTICLE}

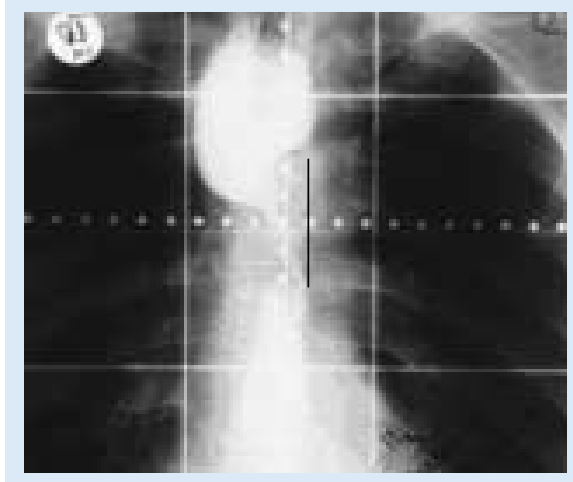

Fig. 1. Simulator film with grid (vertebral length $=$ 2.5 vertebrae $=6.25 \mathrm{~cm}$, grid length $=5 \mathrm{~cm}$ ).

field for treatment were localised and marked. The localised centre was tattooed and a lead wire placed at the centre. This procedure facilitated the positioning of the high dose rate (HDR) treatment catheter and assessment of the treatment length. Patients received premedication with pethidine and Buscopan 30 minutes before the procedure. The pharynx was anaesthetised with a topical spray using xylocaine $4 \%$. The brachytherapy tube was inserted under fluoroscopic guidance ${ }^{6}$ and fixed in position using a face mask.

In the present procedure, insertion of the catheter is done under fluoroscopic guidance after giving Hexabrix to demarcate the proximal end of the lesion. Most of the time, the distal end of the lesion cannot be delineated without giving Hexabrix 3 - 4 times with repeated fluoroscopy. The length of the lesion is therefore estimated by correlating with the number of vertebrae from the Hexabrix swallow performed in the radiology department (each vertebra is taken to measure $2.5 \mathrm{~cm}) .7,8$

Table I shows the estimated length of the lesion using the number of vertebrae, the length as measured using a simulation film with grid and the dif-

\begin{tabular}{|lccl}
\hline & Table 1. Lesion length on Hexabrix swallow & \\
\hline Patient number & $\begin{array}{c}\text { Vertebral height } \\
(\mathbf{c m})\end{array}$ & $\begin{array}{c}\text { Simulator magnification } \\
\text { grid length }(\mathbf{c m})\end{array}$ & $\begin{array}{l}\text { Difference } \\
(\mathbf{c m})\end{array}$ \\
\hline & 12.00 & 10.00 & 2.00 \\
1. & 8.00 & 6.00 & 2.00 \\
2. & 8.50 & 6.00 & 2.50 \\
3. & 7.50 & 6.00 & 1.50 \\
4. & 9.50 & 8.00 & 1.50 \\
5. & 7.50 & 6.00 & 1.50 \\
6. & 6.50 & 5.00 & 1.50 \\
7. & 6.25 & 5.00 & 1.25 \\
8. & 6.50 & 5.00 & 1.50 \\
9. & 8.00 & 6.00 & 2.00 \\
10. & & & \\
& 8.02 & 6.30 & 1.72 \\
Mean $(\mathrm{cm})$ & 7.75 & 6.00 & 1.50 \\
Median $(\mathrm{cm})$ & 6.25 & 5.00 & 1.25 \\
Minimum $(\mathrm{cm})$ & 12.00 & 10.00 & 2.50 \\
Maximum $(\mathrm{cm})$ & & & \\
\hline
\end{tabular}

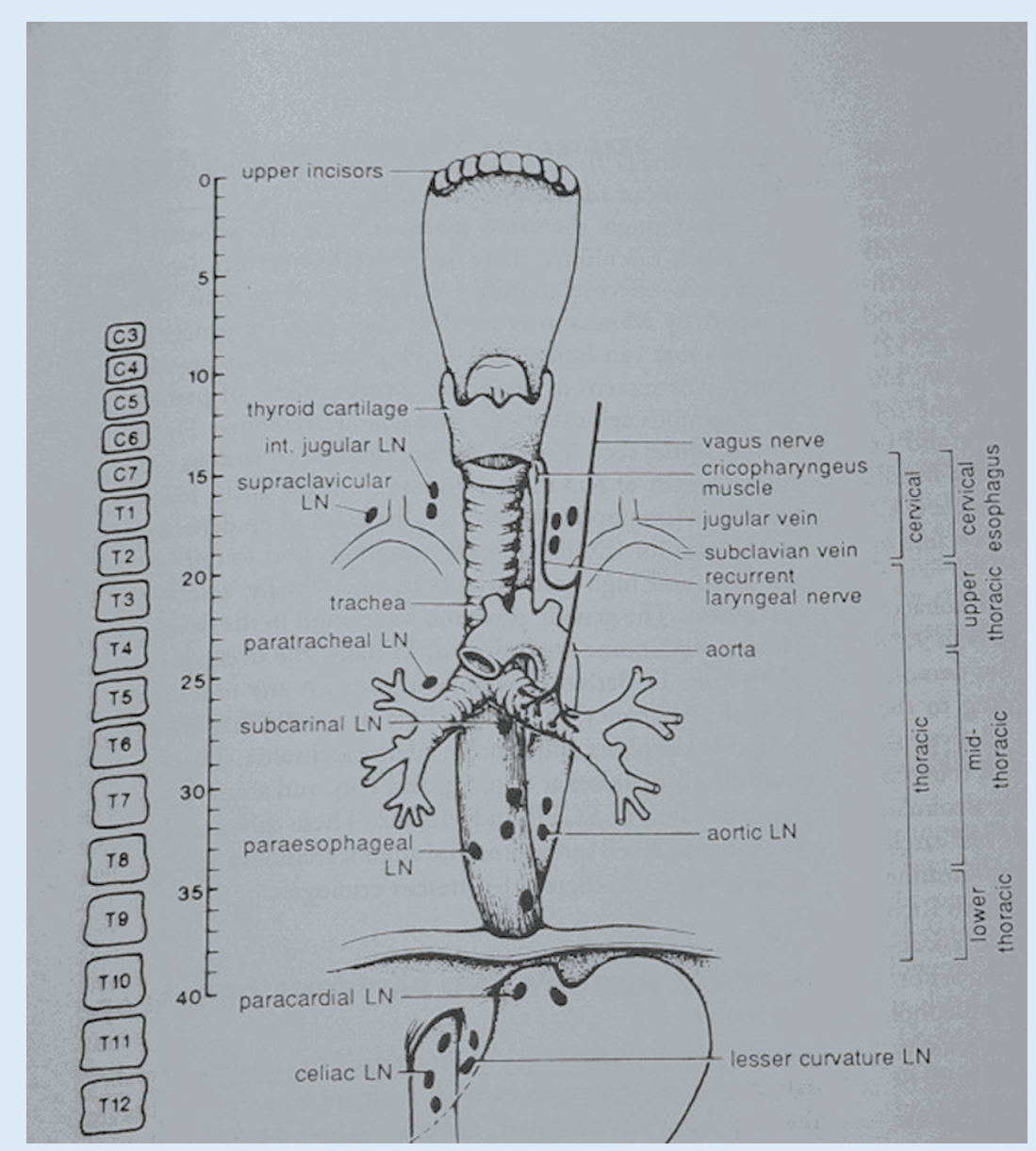

Fig. 2. Basic anatomy of the oesophagus showing four vertebrae $=10 \mathrm{~cm}$. 
ference between these two lengths. The lengths according to vertebrae height were $6.25-12.0 \mathrm{~cm}$ (i.e. 2.5 vertebrae to 5 vertebrae), whereas the lengths according to the magnification graticule with grid were $5-10 \mathrm{~cm}$, the difference being $1.25-2.50 \mathrm{~cm}$ (mean $1.72 \mathrm{~cm}$, median $1.5 \mathrm{~cm}$ ).

\section{Discussion}

Most patients with carcinoma of the oesophagus present with difficulty in swallowing as their main symptom. The role of intraluminal brachytherapy is to relieve the dysphagia without increasing the side-effects by treating minimal normal oesophageal mucosa. The present procedure of estimation of the length of the lesion by estimating the vertebral length is recommended by Potter and Limbergen $^{7}$ and is depicted by Denittis ${ }^{8}$ (Fig. 2). The modified technique of doing prior simulation has already been published by us. ${ }^{6}$

The advantages of the modified technique are: (i) accurate assessment of the length of the lesion; (ii) reduction in treatment length as well as normal mucosa treated, thereby decreasing the morbidity of treatment -related strictures and ulceration; (iii) reduced staff exposure as repeated fluoroscopy is eliminated; and (iv) reduced chance of Hexabrix aspiration in patients as the modified technique is performed before sedation and topical anaesthesia.

\section{Conclusion}

Accurate assessment of the lesion length on Hexabrix will reduce normal mucosa irradiation and decrease the toxicity of the treatment. It is recommended that the change in clinical practice done at our centre be evaluated by other groups.

\section{References}

1. Sur RK, Donde B, Levin CV, Mannell A Fractionated high dose rate intraluminal brachytherapy in palliation of advanced esophageal cancer. Int J Radiat Oncol Biol Phys 1998; 40: 447-453.

2. Rider WD, Mendoza RD. Some opinions on the treatment of cancer of esophagus. Am J Roentgenol Radium Ther Nucl Med 1969; 105: 514-517.

3. Mannell A, Murray W. Oesophageal cancer in South Africa. A review of 1926 cases. Cancer 1989; 64: 2604-2608.

4. Sharma V, Dinshaw KA, Agarwal JP, et al. Intraluminal brachytherapy for palliation of advanced / recurrent carcinoma of the esophagus. J Brachytherapy International 1999; 15: 85-92.

5. Sharma V, Mahantshetty U, Dinshaw KA Deshpande R, Sharma S. Palliation of advanced /recurrent esophageal cancer with high dose rate brachytherapy. Int J Radiat Oncol Biol Phys 2002; 52: 310-315

6. Dinshaw KA, Sharma V, Pendse AM, et al. The role of intraluminal radiotherapy and concurrent 5 Fluorouracil infusion in management of carcinoma esophagus.: A pilot study. J Surg Oncol 1991; 47: 155-160.

7. Potter R, Limbergen EV. Oesophageal cancer In: Gerbaulet A, Potter R, Mazeron JJ, Meertens $\mathrm{H}$, Limbergen EV, eds. The GEC ESTRO Handbook of Brachytherapy. Leuven, Belgium: ESTRO, 2002: 515-537.

8. Denittis AS. Esophagus. In: Perez CA, Brady LW, Halperin EC, Schmidt-Ullrich RK, eds. Principles and Practice of Radiation Oncology. Philadelphia: Lippincott, Williams and Wilkins, 2004: 1282-1304. 